\title{
EDUCAÇÃO, DIREITO E VIOLÊNCIA: REFLEXÕES COTIDIANAS
}

\author{
EDUCATION, LAW AND VIOLENCE: DAILY REFLECTIONS
}

Aldair Oliveira de Andrade ${ }^{1}$, Wagner dos Reis Marques Araújo e Antonio Marcos de Oliveira Siqueira ${ }^{3}$

1 Programa de Pós-Graduação em Ciências e Humanidades (PPGCH), Universidade Federal do Amazonas, Humaitá/AM, Brasil, aldairandrade@yahoo.com.br

2 Universidade do Estado de Minas Gerais, UEMG-Carangola/MG, Brasil, marquesreis@hotmail.com

3 Universidade Federal de Viçosa, Viçosa/MG, Brasil, antonio.siqueira@ufv.br

\section{ARTICLE INFO}

Article history:

Received 2019-06-27

Accepted 2019-06-30

Available online 2019-06-30
Palavras-chave: Educação. Direito. Violência. Cotidiano. Apresentação.

Keywords: Education. Law. Violence. Presentation.

Neste segundo número do volume 2 (2019) da Revista Relações Sociais fazemos mais um ataque frontal com o único instrumento que acreditamos capaz de transformar a realidade social, o mundo vivido, a pena, a letra, o discurso, a reflexão.

O Corpo Editorial e seus colaboradores acreditam que a pena tem mais poder que a espada, pois somente aquela pode modificar aquele que empunha a espada e pode modificar a própria natureza humana. Oportuna a afirmação de Jaerger (2001, p. 10) "uma educação consciente pode até mudar a natureza física do homem e suas qualidades, elevando-lhe a capacidade a um nível superior".

Usamos a pena, ousamos com ela e por ela na construção e transformação da realidade social, do universal, do nacional, do local, do micro espaço, onde exista gente, onde existam homens e mulheres que ainda não alcançaram e nem se colocaram a caminho de construção de um mundo melhor. Parece pouco nossa contribuição, no entanto, é pertinente compreender que mesmo a corrente mais forte, produzida do material mais resistente do universo, carrega em si um princípio essencial, é feita por elos, e nós somos apenas um elo, sem o qual e pelo qual a corrente não existe ou não existiria.

Neste volume trazemos temos interessantes, o que nos remente a refletir com pensadores como, Werner Jaeger, Alfred Schutz, Friedrich Nietzsche, Hannah Arendt, Theodor Adorno, Jessé de Souza, entre outros. Assim, nos lembremos do projeto iluminista que preconizava que o uso da razão livraria a humanidade, da barbárie, da vilania, causado 
pela ignorância, em suma do obscurantismo. No entanto, tal projeto não chegou a termo, pois muito embora tenhamos avançado no processo civilizatório paradoxalmente avançamos na barbárie, pois "o sono da razão produz monstros" (CASTRO, 2012). Não menos oportuno lembrar do filósofo da suspeita Nietzsche (2004), quando afirma que é necessário construir um novo modo de educação dos jovens, pois o modelo criado sob os auspícios do iluminismo produziu uma cultura de verniz, uma cultura de salão.

São tempos obscuros, tempos cinzentos, tempos em que urgem uma reflexão-ação -reflexão (VASQUEZ, 2007) sob novos moldes, pois os quais têm se ancorado a sociedade moderna estão em xeque, estão sobre suspeita, educação e o direito, elementos basilares da sociedade moderna não conseguiram se consolidar como um projeto de emancipação da natureza, da violência. O que se presenciamos por sua vez é a ascensão do não direito, é a negação de princípios fundamentais da sociedade moderna (do iluminismo), liberdade, igualdade e fraternidade. É premente que a formação de jovens esteja ancorada em "ensinar o super-homem" como "sentido da terra" (NIETZSCHE, 2011)

Neste volume, propomos uma reflexão em três etapas que se alinham e se retroalimentam, a educação, o direito e a violência. Digamos se alinham, pois, numa perspectiva transnacional, regional ou local, estes elementos fazem parte da inventividade, portanto da vida e trajetória do homem no mundo. Iniciamos nossa odisseia pela reflexão sobre o processo de formação educacional colombiana, reprovação e evasão escolar; saímos da América do Sul e vamos para o Norte, refletir sobre o processo de dessegregação em escola secundarista norte americana; retornamos para uma discussão do processo educacional tipicamente brasileiro, a educação de jovens e adultos seja no ensino fundamental e adultos; avançamos para a pedagogia na alternância na educação do campo brasileira. Partimos da reflexão dos processos educacionais e culturais, nos aventuramos numa discussão sobre a síndrome alcoólica fetal e suas consequências, o que nos remete ao texto seguinte em que o álcool retoma como protagonista potencializar da violência conjugal. Ingressamos no último bloco de discussões, começamos com o direito e a educação profissional, a contribuição da sociologia das profissões, damos uma parada para refletir sobre a cultura judaico-cristã e a construção do machismo, com o texto sobre os processos religiosos, e para fechar este volume somos brindados com a discussão sobre os indivíduos e sua integração à sociedade informacional.

Essas são pitadas, aperitivo do que este volume reserva, um banquete reflexivo sobre o mundo da vida (SCHUTZ, 1979), pois entendemos que o que está em jogo é o projeto de transformação da realidade tão desigual, preconceituosa, violenta, machista, etc. Precisamos transformar o mundo, e para isso acreditamos que substrato para fazê-lo está na compreensão da realidade ácida, crua e dura que nos cerca. 
No primeiro artigo "Regazo y abandono educativo en Colombia: un cambio em la política pública para la equidad educativa", a autora Ángela Maria Rojas Ladino, em sua análise da política pública colombiana em torno dos problemas educativos propõe numa perspectiva institucional uma intervenção que aborde as causas fundamentais o atraso e do abandono escolar. A autora entende que tais propostas alterariam efetivamente a realidade educacional colombiana, desde que implementadas efetivamente duas ações que se complementam: ampliação da jornada de trabalhado, maior permanência dos jovens na escola e a abordagem da ideia de escola democrática no processo formativo.

No artigo, "Hannah Arendt e a questão negra na dessegregação da escola de Little Rock, 1957", de Danilo Arnaldo Briskievicz, e Amauri Carlos Ferreira, nos sacodem bruscamente e nos lançam na cara um fato comum, o processo de discriminação racial, um processo podemos dizer, naturalizado historicamente no Brasil, ranço do processo de formação cultural (SOUZA, 2017). O que o artigo traz de novo, o posicionamento político e controverso da filósofa Arendt. Considerado por muitos "antipático", "insensível". Um artigo extremamente rico, pois no remete a uma reflexão cuidadosa, ao mesmo tempo, árduo sobre segregação e desagregação. Podemos mesmo afirmar que este artigo é extremamente oportuno quando nos remente como leitor a uma emparedamento sobre nossa compreensão de raça e cultura.

Ada Guimarães Ribeiro e Regina Magna Bonifácio de Araújo, nos lançam a uma reflexão sobre a educação de crianças nos anos iniciais, quando discutem "O que revelam as pesquisas sobre as classes multisseriadas nos anos iniciais do Ensino Fundamental da EJA?". É inegável o avanço brasileiro nas últimas décadas na inclusão educacional, como também é inegável que ainda há muito o que fazer para que o país alcance a democratização do processo ensino aprendizagem. O presente artigo nos leva a questionar porque temos tão poucas pesquisas sobre essa modalidade, quais são os elementos impeditivos institucionais ou burocráticos ou mesmo subjetivos que impossibilitam maior visibilidade desse novo e desafiante processo de ensino aprendizado.

Presenciamos um quase completo fracasso do modelo iluminista de educação, se ele se propunha tirar a humanidade das trevas, conduzindo-a a liberdade, igualdade e fraternidade. O que tudo indica este projeto foi um retumbante fracasso. Cremos que está na hora de repensarmos este projeto. Talvez "A Pedagogia da alternância como proposta de educação no campo: um estudo na escola família agrícola Itapirema em Rondônia, Brasil" de Claudineia Ferreira dos Santos e colaboradores, nos ajudem a repensar o projeto de formação dos jovens. Adorno (2003), ao repensar Auschwitz, afirmava que era necessário repensar o projeto de formação educacional, somente assim tal tragédia não se repetiria.

Eduardo Jorge Sant'Ana Honorato e colaboradores nos rementem a uma questão extremamente complexa e ao mesmo tempo corriqueira, quando nos revelam "Aspectos 
psicojurídicos da síndrome alcoólica fetal”. Para eles, a SAF está se tornando um problema de saúde pública, tendo em vista que esta é uma das maiores causas de atraso mental, que mesmo não tenho cura pode ser prevenida pela abstinência alcoólica no período gestacional. Para os autores o trabalho coordenado pela família e por psicológicos são fundamentais no processo de prevenção e que evitaria causar qualquer dano ao feto em formação.

Em "Violência conjugal associada ao uso abuso de álcool: uma revisão sistemática integrativa", Eduardo Jorge Sant'Ana Honorato e colaboradores nos lançam um elemento a mais sobre os efeitos noviços do consumo e álcool, a violência conjugal. A pesquisa analisa a publicações sobre o tema numa perspectiva quantitativa e qualitativa, descrevendo tipos de práticas recorrentes no período de 2009 a 2015. O levantamento apontou resultado qualitativo extremamente significativo, comprovando que o uso do álcool é elemento potencializador de violência na relação conjugal.

Em a "Cultura Jurídica e Educação Profissional: análise dos discursos proferidos pelo deputado Francisco Mendes Pimentel no trâmite da Lei Estadual 203/1896", de Débora Castro Alves e Irlen Antônio Gonçalves, os autores constaram que o uso de várias técnicas argumentativas próprias do discurso político, aliadas a formação jurídica foram fundamentais na aprovação do projeto de Lei que culminou na aprovação da Lei 203, de 18 de setembro de 1896.

Em "Contribuição da sociologia das profissões para a análise das profissões de arquivista e museólogo no Brasil" Tainara dos Santos Alves analisa as profissões de arquivista e museólogo no Brasil. Seu trabalho demonstrou que o diploma de nível superior é determinante para distinguir conceitos de profissão e ocupação, destacando o papel do Estado nas determinações profissionais. Destaca também que cada profissão possui um campo de atividade exclusivo e um residual de atuação, e mesmo que há um amparo jurisdicional sobre a exclusividade do exercício da profissão, há sempre investidas de alguns grupos na disputa do mercado de trabalho.

Ingrid Mesquita Coelho e colaboradores nos trazem uma reflexão sobre o "Os processo religiosos judaico-cristão e a construção do machismo". Para os autores, em sua pesquisa em livros, artigos e teses, o discurso judaico-cristão influenciou durante toda a história da humanidade para violência e exclusão feminina, e mesmo que Jesus tenha lutado por igualdade entre os gêneros, seus ensinamentos foram sufocados pela cultura patriarcal e perduram até a atualidade.

E por último e não menos importante, fechamos este volume com uma discussão trazida por Wagner dos Reis Marques Araújo e Ayla Yumi Higa, "Interações e Sociabilidades digitais na Sociedade Informacional". Para os autores nos anos 2000 a internet se transformou em uma ferramenta inovadora e essencial para o sujeito na era da comunicação, seu uso 
racional proporciona descobertas e possibilidades de reformulações da subjetividade do Ser pós-moderno, e que a revolução tecnológica e a transformação do social estão ligadas a penetrabilidade da informação por toda a estrutura social, da que o grau de desenvolvimento das sociedades.

Este volume, como um nó górdio traz uma tessitura do real, um enigma a ser desvendado, nos resta a solução.

\section{REFERÊNCIAS}

ADORNO, T. W. Educação após Auschwitz. In: Educação e Emancipação. $3^{\underline{a}}$ ed. São Paulo: Paz e Terra, 2003.

CASTRO, V. V.. Bruxas e monstros nas representações pictóricas de Goya. diversidade religiosa: Revista da Graduação em Ciências das Religiões - UFPB, , v. 1 n. 2, p. 1 - 10, 28 set. 2012.

JAEGER, W. Paideia: A formação do homem grego. 4ํㅡㄹ ed. São Paulo: Martins Fontes, 2001.

NIETZSCHE, F. Assim Falou Zaratustra. Tradução, notas e posfácio de Paulo César de Souza. São Paulo, 2011. Companhia das Letras.

.Escritos sobre Educação. Tradução de Noéli Correia de Melo Sobrinho.

Rio de Janeiro:Puc-Rio; São Paulo: Loyola, 2004.

SOUZA, J. A ELITE DO ATRASO: da escravidão a lava jato. Rio de Janeiro: Leya, 2017.

SCHUTZ, A. Textos escolhidos de Alfred Schutz. In: WAGNER, Helmut R. Fenomenologia e Relações sociais. Textos escolhidos de Alfred Schutz. Organização e introdução de Helmut R. Wagner. Tradução de Ângela Melin. Rio de Janeiro: Zahar Editores, 1979.

VAZQUES, A. S. Filosofia da Práxis. São Paulo: Expressão Popular/Clasco, 2007 